\title{
Correction to: Anthropogenic food resources, sardine decline and environmental conditions have triggered a dietary shift of an opportunistic seabird over the last 30 years on the northwest coast of Spain
}

\author{
Joana G. Calado ${ }^{1,2,3}$ • Vítor H. Paiva ${ }^{2}$ Jaime A. Ramos ${ }^{2}$ - Alberto Velando ${ }^{3}$ Ignacio Munilla ${ }^{4}$ \\ Published online: 12 March 2020 \\ (C) Springer-Verlag GmbH Germany, part of Springer Nature 2020
}

Correction to: Regional Environmental Change (2020) 20:10

https://doi.org/10.1007/s10113-020-01609-6

The published article contained several errors in Table 1. The rows "Polybius henslowii" and "Pollicipes cornucopia" had been exchanged, as well as Vegetable matter, Insects, and Terrestrial vertebrates. The corrected table is provided here.

The online version of the original article can be found at https://doi.org/ 10.1007/s10113-020-01609-6

\footnotetext{
Joana G. Calado

joana.gomes.calado@gmail.com

1 Molecular and Environmental Biology Centre (CBMA),

Universidade do Minho, Campus de Gualtar,

4710-057 Braga, Portugal

2 MARE - Marine and Environmental Sciences Centre,

Departamentode Ciências da Vida, Universidade de Coimbra, 3004-517 Coimbra, Portugal

3 Animal Ecology Group, Universidade de Vigo, Lab 97, Torre CACTI, Campus As Lagoas, Vigo, Spain

4 Munilla Biodiversidade, San Pedro 94, 15703 Santiago de Compostela, Spain
} 


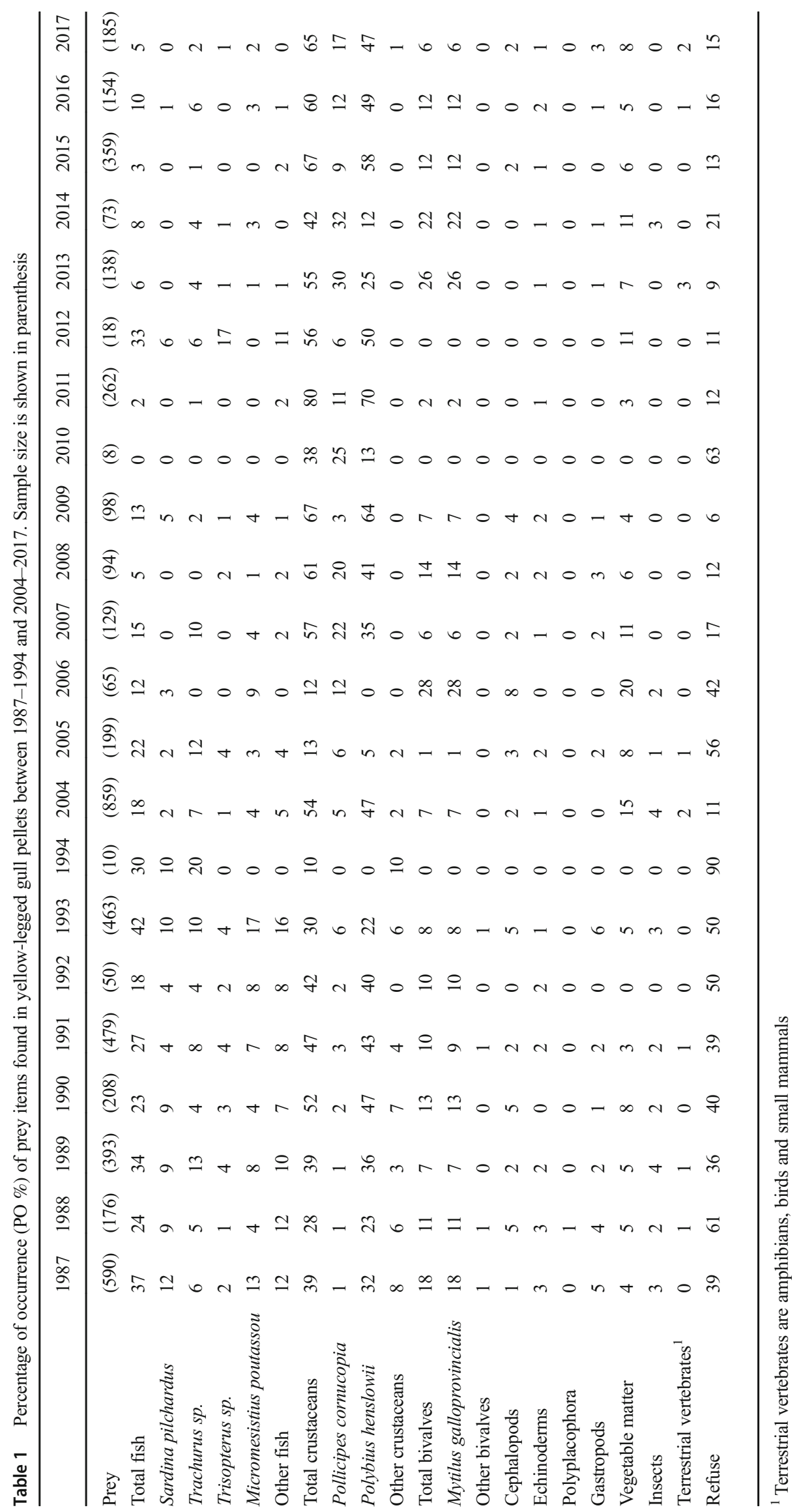

